\title{
ERROR AND DISCOVERY IN FUNDUS DISEASE*†
}

\section{BY}

\author{
I. C. MICHAELSON \\ Hadassah University Hospital, Israel
}

THERE is a tendency, to me rather depressing, to emphasize the role of chance in scientific discovery, and Reese (1958) has recently detailed the place of serendipity in ophthalmology. It will be remembered that in the fairy story, the three princes of Serendip looked for one thing and found another more desirable; but their technique does not seem to apply to discoveries in the fundus of the eye. In discovery, generally, chance may indeed give the prize to a particular discoverer, brilliant, painstaking, or otherwise; but discoveries awaiting to be discovered arrange themselves in a sequence fixed by a determinable logic. This logic in the discovery of fundal diseases is the principal theme of this paper. The discoverers may be accidental, but the discoveries are not.

The sense of logic in these discoveries is further heightened, as we shall see, by the fact that in each disease of the fundus, at each stage, the discoverers, brilliant, painstaking, or both, applied themselves consciously to the solution of that stage's problems, and chance did not give her prize to an outsider. Perhaps this happened because the ocular fundus is somewhat off the beaten track of the casual observer.

Understanding of fundal diseases as of all diseases requires a knowledge of the clinical pattern, of the initial lesions from which the clinical pattern evolved, of the events leading up to the initial lesion, and finally of the treatment of these events. We can, therefore, divide the acquisition of the knowledge into four phases:

(1) The determination of the static ophthalmoscopic picture, where the initial lesion is yet unknown.

(2) The discovery by ophthalmoscopy of the initial lesion, and, therefore, of the evolving clinical pattern.

(3) The discovery of the events leading up to the initial lesion. This frequently involves the reproduction of the disease in animals.

(4) The application of the facts learned in the previous phases to experimental therapy in man.

* Received for publication November 3, 1959.

$\dagger$ Lecture given at the University of Glasgow on April 19, 1959, on the occasion of the award of the Mackenzie Memorial Medal. 
Our understanding of retinal disease has gone through these four phases in this order. This I hope to demonstrate as we proceed by discussing diabetic retinopathy, retinal detachment, retrolental fibroplasia, hypertensive retinopathy, and disciform degeneration.

The passage from phase to phase was often made difficult by established errors which lay across the path, and these, too, will be mentioned; not in criticism of our teachers or of our teachers' teachers, but because they illustrate the difficulties that medicine must always surmount in its phases of discovery. There is hardly ever in medicine a void into which the truth may advance, there is always an established misconception to dislodge. This is natural because we are dealing with the sick, whose appetite for diagnosis, prognosis, and therapy is not always to be postponed, and for which every generation must cater as best as it can.

As we go on it will be seen to be important to show where fundal discovery depends on the clinician and where on the basic scientist such as the biochemist or biophysicist. Medicine, like the visual arts, is becoming less clinical and more abstract or semi-abstract. That is to say it is running away from the immediate problem of the individual in search of more basic or "purer" truths, the process called basic or pure science. Just as the painter may ask himself where his realism or if you like to call it clinical portraiture is leading him, so the ophthalmologist might ask himself if it would not be better for the sake of discovery to leave the dark room for the laboratory. As we shall see, as you already know, this is often advisable; but it is of interest for a study of the nature of discovery to indicate where the realism of the ophthalmoscope and where the abstraction to the laboratory are needed.

With these intentions and generalizations in mind, we can now proceed with what we know of certain fundal diseases.

\section{DIABETES}

The "static" ophthalmoscopic picture of diabetic retinopathy (Phase 1) was described by Jaeger (1856); yet if one consults a standard text-book published before 1943 the clinical description of the retinopathy is still confined almost entirely to a detail of circular haemorrhages and solid-looking exudates, and the possibility of severe intra-ocular haemorrhage into the vitreous. The lesions, except in their degree, do not arrange themselves into an evolving pattern. The initial lesion, the presence of micro-aneurysms, is not emphasized, although they had been described by Mackenzie and Nettleship in 1877. Doubts are even expressed whether there is such an entity as diabetic retinopathy, many authors being of the opinion that the condition is merely a variant of hypertensive retinopathy occurring in a diabetic subject. They point out that the blood pressure is frequently raised in this condition which, moreover, appears to be unrelated to the 
degree of hyperglycaemia. Duke-Elder (1940) summarized the position by stating that pathological investigations revealed little peculiar to the condition. These doubts probably did much to discourage the minute and careful observations which later enabled Ballantyne and Loewenstein (1943) to establish the initial lesion and therefore finally the identity of the condition. Histology at this stage offered little to diminish the diagnostic doubts of ophthalmoscopy.

It was not, then, until 1943 that Phase 2 was reached. Ballantyne and Loewenstein (1943) and later Friedenwald (1949) and Ashton (1949) showed that the primary change is a disturbance of the capillary basement membrane, from which is evolved a series of progressive changes: capillary dilatation, aneurysm formation, haemorrhages, exudates, venous stasis, new vessel formation, and in many cases blindness from severe vitreous haemorrhage. The evolution of the clinical pattern was made clear for the first time after almost a century of ophthalmoscopy and there could now be no doubt that diabetic retinopathy was a disease sui generis distinct from hypertensive retinopathy. The initial lesion in the capillary basement membrane consists at least in part of a mucoid or mucoprotein thickening, with consequent capillary wall dilatation and aneurysm formation. The way was now open for a search into the cause of the initial lesion. This was obviously not hyperglycaemia to which the retinopathy bore no direct relationship.

The opening of Phase 3 of our understanding may in a sense be said to have begun when Ashton (1949) showed that the nephropathy peculiar to diabetes-Kimmelstiel-Wilson disease-occurred almost exclusively in cases of diabetes showing retinopathy. The histological similarities between the retinal and renal changes in diabetes were pointed out by Becker, MaengwynDavis, Rosen, Friedenwald, and Winter (1954).

A series of studies, chiefly biochemical and endocrinological, published between 1952 and 1954 suggested that the initial lesion in the retinopathy was the end result of a sequence of events including overactivity of the adrenal cortex with a resulting or associated defect in the mucopolysaccharide metabolism (Friedenwald, 1952, 1953; Becker, Allen, Winter, MaengwynDavies, and Friedenwald, 1954; Becker, Lang, and Chow, 1953; Good, Good, Kelley, and Glick, 1951; Berkman, Rifkin, and Ross, 1953; McManus, 1950). Success in the production of diabetic retinopathy in alloxanized rabbits given large doses of cortisone was reported by Becker (1952). Recently, however, certain authors have expressed doubt that overactivity of the adrenal cortex plays a role in the pathogenesis of the retinopathy. Rifkin, Solomon, and Lieberman (1958) found no increase in the urinary secretion of 17-hydroxycorticosteroids in cases of diabetic retinopathy; Becker's success in producing diabetic retinopathy experimentally in rabbits has not been reproduced by others, and despite the use of large doses of cortisone in many conditions the occurrence of retinal micro-aneurysms is extremely rare. We may, therefore, summarize the present state of Phase 3 by noting 
that the evidence although suggestive, is conflicting. Until the disease has been definitely reproduced experimentally in the retina the consummation of this phase must remain in doubt, although its progress has in the meantime been tentatively measured by therapeutic experiments in man.

Phase 4, therapeutic experimentation, has not been touched with success. The treatments resorted to on the basis of the evidence regarding the pathogenesis of the initial lesion include removal of the pituitary gland, adrenalectomy, and the exhibition of testosterone. Lack of success has discouraged further efforts in these directions, and we await more information regarding the events leading to the initial lesion.

\section{Retinal Detachment}

Phase 1 of our knowledge of retinal detachment began almost with the discovery of the ophthalmoscope. Coccius (1853) noted the presence of the retinal hole but without appreciating its significance. Phases 2 and 3 began together 30 years later thanks to the remarkable genius of Leber (1882), who, in one single report, established the significance of the retinal hole as the initial lesion and demonstrated the importance of vitreous pull on the retina. Phase 4 was embarked upon when Gonin $(1925,1927,1929)$ showed that it was possible to cure the detachment by electrocautery of the retinal hole.

Before 1882 retinal holes had been only occasionally reported in cases of retinal detachment. They were generally considered to be the result of the detachment and to permit the subretinal fluid, a product of the chorio-capillaris, to pass into the vitreous. They were considered by some observers to help in this way to reduce the detachment and, therefore, to be favourable to prognosis. Puncturing holes in the retina was even suggested as a mode of therapy.

Leber (1882) brought forward proof that the hole was the initial lesion in retinal detachment, and he thereby confirmed the findings of de Wecker (1870), who had reported that in the previous 2 years he had examined his cases most carefully and had found that every fresh one had a retinal hole. de Wecker had also stated that the hole had appeared in the quadrant appropriate to the initial visual symptoms of clouding and flashes. In this remarkable report of 1882, Leber also encompassed the Phase 3 by showing that the factors leading to the initial lesion were vitreous traction and cystic degeneration of the retina. He confirmed the point, already made by Iwanoff (1869), that retinal detachment was always preceded by vitreous detachment, indicated the fluid interval between the detached vitreous and the retina, explained the morphology of a horse-shoe hole on the basis of a pull by the vitreous on the flapped lid, and discussed his histological findings of adherence between vitreous and retina. Leber even explained that "light 
flashes", were not succeeded by the appearance of a hole or detachment, when the vitreous pull was insufficient to tear the retina. He further completed Phase 3 by giving details of his experimental reproduction of the disease in rabbits. Iron, copper, and lead foreign bodies placed in the vitreous of rabbits produced a band formation which pulled on the retina and caused retinal holes and detachment within a few days of the commencement of the experiment. The general acceptance of this explanation of the events leading up to the initial lesion awaited the confirmatory finding of Deutschmann (1895), Gonin (1904), and others, and of those who had the technical advantage of slit-lamp microscopy of the fundus (Goldmann, 1954), but there is little doubt that credit for this phase of discovery belongs to Leber.

The concept of the pre-initial lesion phase, as suggested by Leber and since generally accepted, is that of a senile or myopic degeneration occurring simultaneously in vitreous and retina. The pre-initial lesion phase may consist of other circumstances and in this connexion I should like to mention the evidence that a specific ischaemic retino-choroiditis may lead to hole formation (Gonin, 1923; Michaelson, 1955, 1956). In this condition there is a local secondary vitreous fibrillary formation which by its retraction tears the ischaemic retina. It is quite possible that more than one set of circumstances may lead to the initial lesion of a retinal hole.

Leber (1882) concluded his report by regretting that he had no therapy to offer based on his findings. He was close to the promised land, but it was not given him to enter it; it was not until about 40 years later that Gonin performed the therapeutic experiment in man of closing the retinal hole by electro-cautery, which has since been the basis of our therapy (Gonin, 1925, 1927, 1928).

The cause of the initial lesion, cystic degeneration of the retina and vitreous adhesions, has not received the same therapeutic attention as the lesion itself, but in some clinics an attempt has been made to prevent detachment by the diathermy or photocoagulation of these early changes. A national co-operative study is being carried out in Israel to assess desirability of such interventions. The six main ophthalmic departments are carrying out a uniform study of the incidence of retinal detachment in myopic eyes, phakic or aphakic, with or without detachment in the fellow eye, and also in all eyes whose fellow has had a retinal detachment. An attempt will be made to assess the prognostic significance of certain types of retinal and vitreal changes. The diagnostic criteria are standardized, and these findings will allow uniform surgical procedures to be planned which may lead to statistically valid replies to the question of the desirability of prophylactic treatment of retinal detachment. Photocoagulation, as described by MeyerSchwickerath (1959), presents wide possibilities in this regard. 


\section{RETROLENTAL FibROPLASIA}

Phase 1 of the discovery of this disease began when Terry (1942) gave a histological description of the vascular fibrous mass present behind the lens in premature infants. He gave cogent reasons for its not being a cyclitic membrane, and was of the opinion that it was a fibroplastic overgrowth of a persistent tunica vasculosa lentis or of the entire vascular structure in the foetal vitreous. In the light of this assumption, it seemed reasonabie to many investigators to discuss the antenatal factors which might have acted on the vitreous vessels, which normally disappear 6 weeks before birth. Anoxia of the foetus in the womb was thought of, and in this connexion experiments were carried out with pregnant mice which demonstrated that if they were partially deprived of oxygen a certain percentage of their new-born offspring showed an abnormal persistence of the hyaloid system. Moreover, on the basis of the condition being due to haemorrhages from this system, vitamin $\mathrm{K}$ was used. It also seemed reasonable to attempt to close the hyaloid artery by surgical means.

This was Phase 1 of discovery with its frustrations of diagnosis and therapy. Phase 2 was carried out by Owens and Owens (1949), Friedenwald, Owens, and Owens (1951), and Heath (1951), who clearly showed by histological and clinical examination that the condition was primarily a vascular retinopathy affecting the growing retinal capillaries which in the premature infant continued to grow after birth. The other manifestations of the disease, new vessels in the vitreous, retinal detachment, and vascularized membrane behind the lens, were shown to be merely the end products of the spread of the abnormal retinal neovasculature through the internal limiting membrane. The evolving pattern from the initial lesion to the last scene was now clear, but the therapy that it suggested was of no help. ACTH was given in large doses in an attempt to arrest the new vessel growth.

The next phase of discovery, the cause of the initial lesion, that is the abnormal retinal neovascularization, was completed in 1952, although Michaelson (1948) and F. W. Campbell (1951) had already brought forward sufficient evidence that the concentration of oxygen in the retina was a deciding factor in the development of new vessels in the retina. The capillaries in the retina first develop from the side of the vein remote from the neighbouring artery, and only later grow from the side of the vein close to the artery. In their further growth they never quite reach the artery but leave a space around it which is capillary-free throughout life. This periarterial capillary-free zone is about $100 \mathrm{~m} \mu$. in average width, but can be reduced in size by lowering the atmospheric pressure. The clinical evidence for the significance of an abnormal oxygen concentration soon began to arrive, especially in the reports of K. Campbell (1951), Crosse and Evans (1952), Ryan (1952), Jefferson (1952), and Szewczyk (1952). These authors 
showed that most of the patients with retrolental fibroplasia had been kept in incubators for a more or less lengthy period and had during that time received oxygen in concentration of 50-70 per cent. Children who had not been kept in abnormal concentrations of oxygen did not develop the disease. Phase 3 was completed when Ashton, Ward, and Serpell (1953) and Patz, Eastham, Higginbotham, and Kleh (1953) produced the disease by placing mice and kittens in abnormal oxygen concentrations.

Phase 4 came between 1954 and 1955, when human clinical experiments carried out by Kinsey (1956) in a national cooperative study, showed that the disease could be prevented by removing the cause of the initial lesion, that is the exposure of the infant to abnormally high concentrations of oxygen.

Thus it may be said of retrolental fibroplasia that the disease is almost completely understood and is to that extent within our powers of diagnosis, prognosis, and treatment.

\section{HYPERTENSION}

The static phase in hypertension was described by Ballantyne (1937) and Friedenwald (1947):

(1) Narrowing of the vessels due to angiospasm or hypertonus of the vessel wall.

(2) Calibre variation usually due to local hyperplasia of the vessel wall.

(3) Changes at the arterio-venous crossings (chiefly Gunn's sign) due to hyperplasia of the vessel walls and lack of retinal transparency.

(4) Fullness of the vessels due to increased diastolic pressure.

The evolution of the clinical and histological appearances has been explained more or less completely only by Leishman (1957). The degree of hypertonus is a measure not only of the hypertensive process but also of the capacity of the vessel wall to respond to that process, that is of the age of the patient and the accompanying involuntary sclerosis. If the hypertension appears in middle age or later, the vessel wall because of the pre-existing sclerosis cannot contract to the same extent as in younger persons. The result is that very high levels of diastolic pressure are not obtained in the older age groups and malignant hypertension is not a sequel to the contraction of the vessel. Leishman has shown that the initial lesion consists not only of the action of the hypertonic factor on the vessel wall, but also of the capacity of the vessel to react, that is of the degree of sclerosis of the vessel wall.

In this further consideration of the evolving hypertensive process in the retina, Leishman has shown that the hypertonic-hyperplastic changes are followed by a reactionary sclerosis, as the result of which the thinned and weakened vessel wall dilates under the influence of the raised blood pressure. 
This implies two facts:

(a) That the vessel fullness is a late effect.

(b) That the vessel previous to its dilatation undergoes a narrowing of diameter.

My experience does not confirm this in all cases. In some cases the fullness of the vessels is certainly a late effect and may be interpreted as Leishman has done, even though there is no definite evidence of its having been preceded by a narrowing of the vessel diameter. In other cases, however, the fullness of the vessels appears fairly early, and it is reasonable to consider it simply as a "tightening" of the vessel wall due to the heightened diastolic pressure. There are very few cases in which it is possible to demonstrate that the fullness of the vessels has been preceded by a stage of narrowing. Be this as it may, Leishman has been an important architect of Phase 2 of our understanding of the behaviour of the retinal vessels in hypertension. Since appreciating the essential truth of his observations, my colleagues and I have made fewer mistakes in diagnosis and prognosis.

Phase 3, our knowledge of the hypertensive factor causing the initial lesion, is dependent on the general clinician and the pathologist. Although in most cases of hypertension there is no known antecedent condition which may be considered as causal, in about 5 per cent. of cases there has been a disturbance of the kidneys or of the adrenal and pituitary glands. The latter conditions (Cushing's disease, phaeochromocytoma) involve overproduction of adrenalin. The process whereby a diseased kidney produces hypertension is not known, although it is probable that it does so by the release of a hypertensive factor into the blood, of which the well known experiments of Goldblatt, Lynch, Hanzal, and Summerville (1934) and Goldblatt (1937) on dogs are suggestive. Whatever the factor may be, its effect on the vessels is mediated by the sympathetic nervous system.

The treatment of hypertension is essentially that of the initial lesion, the overactivity of the sympathetic nervous system and the vessel hypertonus. Both medical and surgical methods have shown notable achievements in this respect. The treatment of the cause of the initial lesion is, however, occasionally possible and is usually confined to nephrectomy or to operation for Cushing's disease or phaeochromocytoma. By these means it has frequently been shown that the papilloedema and retinal haemorrhages or exudates may be greatly diminished or made to disappear.

\section{Disciform Degeneration at the MaCula}

This disease is an example of a retinal disorder in which our knowledge is limited to Phase 1 , the initial lesion not having yet been determined. Although Oeller (1905) first used the title disciform degeneration of the 
macula lutea, Holm (1917) was the first to give a satisfactory clinical description.

Some cases are, from first to last, preponderatingly exudative; others show both exudate or haemorrhage in a relationship which makes it difficult to say which is primary; others have a sudden onset with massive haemorrhage, the exudate being apparently a late development. This is as far as clinical observation has gone.

From the histological examination of the static phase, emerges the fact that an early change is a disturbance of Bruch's membrane. Most authors report changes in this membrane (Junius and Kuhnt, 1926; Wölfflin, 1926; Vogt, 1935; Rintelen, 1937; Braun, 1937; Verhoeff and Grossman, 1937), and very few authors deny it, an assertion which properly would demand examination of all the areas by means of serial sections. The vessels of the choroid are described as normal by most authors.

Despite the accumulated clinical and histological facts, there is not yet sufficient evidence to assume finally that the initial lesion is a change in Bruch's membrane, a vascular fault, or perhaps some other defect. The completion of Phase 2 of discovery may be clinical and may depend on more precise examination of the earliest changes in the fellow eye, or may come from further histological reports on eyes in the earliest stage of the disease. These reports may be concerned with the state of the posterior ciliary vessels and other orbital vessels as much as with the tissues within the eye. The possible presence of a systemic disturbance, for example of the elastic tissue in the skin and elsewhere, may throw light on the state of Bruch's membrane in the subjects of this condition.

It is clear that, until the phase of the initial lesion and the phase of the events preceding it are known, there can be no rational discussion of therapy. The use of heparin is based on the fact that the initial lesion is a vascular fault, an example of the difficulty of placating the natural desire of the patient for some form of therapy for a blinding disease.

\section{Discussion AND CoNCLUSIONS}

From the analysis attempted in a few fundus diseases, which is set out in tabular form opposite, one might perhaps be permitted to indulge in some generalizations. Excluding for obvious reasons retrolental fibroplasia, the first phase of discovery came within a few years of the invention of the ophthalmoscope. The second phase in most of these diseases was completed only a half century or more later and one is therefore tempted to ask what special qualities or facilities were needed for its consummation.

The first undoubtedly is the capacity for prolonged and painstaking observation, with careful note-taking, photography, and sketching. It is especially important if the same case can be followed up over a number of years. This requires great patience as well as judgment and "the art is 
TABLE

PHASES OF DISCOVERY IN FIVE PATHOLOGICAL CONDITIONS OF THE FUNDUS

\begin{tabular}{|c|c|c|c|c|c|c|}
\hline \multicolumn{2}{|r|}{$\begin{array}{l}\text { Phases of } \\
\text { Discovery }\end{array}$} & $\begin{array}{l}\text { Diabetes } \\
\text { Mellitus }\end{array}$ & $\begin{array}{c}\text { Retinal } \\
\text { Detachment }\end{array}$ & $\begin{array}{l}\text { Retrolental } \\
\text { Fibroplasia }\end{array}$ & $\begin{array}{l}\text { Hypertensive } \\
\text { Retinopathy }\end{array}$ & $\begin{array}{c}\text { Disciform } \\
\text { Degeneration }\end{array}$ \\
\hline 1 & "Static" & $\begin{array}{c}1855 \\
\text { ? Hypertensive } \\
\text { retinopathy }\end{array}$ & $\begin{array}{c}1852 \\
? \begin{array}{c}\text { Hole secondary } \\
\text { phenomenon }\end{array}\end{array}$ & $\begin{array}{c}1942 \\
\text { ? Persistent } \\
\text { tunica vasculosa }\end{array}$ & $1890 \mathrm{c}$ & 1917 \\
\hline 2 & $\begin{array}{l}\text { Initial lesions } \\
\text { and evolving } \\
\text { pattern }\end{array}$ & $\begin{array}{l}1943 \\
\text { Micro- } \\
\text { aneurysms }\end{array}$ & $\begin{array}{c}1882 \\
\text { Retinal hole }\end{array}$ & $\begin{array}{c}1949 \\
\text { Capillary } \\
\text { retinopathy }\end{array}$ & $\begin{array}{c}1957 \\
\text { Hypertonus + } \\
\text { Sclerosis }\end{array}$ & $\begin{array}{l}\text { ? Bruch's } \\
\text { membrane } \\
\text { ? Vascular } \\
\text { ? Other }\end{array}$ \\
\hline \multirow[t]{2}{*}{3} & $\begin{array}{l}\text { Cause of initial } \\
\text { lesion }\end{array}$ & $\begin{array}{l}1952 \\
\text { Disturbance of } \\
\text { (a) Adrenal } \\
\text { cortex } \\
\text { (b) Mucopoly- } \\
\text { saccharide } \\
\text { metabolism }\end{array}$ & $\begin{array}{l}1882(1904) \\
\text { Vitreous } \\
\text { traction and } \\
\text { cystic retina }\end{array}$ & $\begin{array}{c}\text { 1948-1953 } \\
\text { Hyper- } \\
\text { oxygenation }\end{array}$ & $\begin{array}{l}\text { (a) Hormonal } \\
\text { (b) Unknown }\end{array}$ & \\
\hline & $\begin{array}{l}\text { Production in } \\
\text { animals }\end{array}$ & Rabbits & Rabbits & Cats and mice & Dogs & \\
\hline \multirow[t]{2}{*}{4} & $\begin{array}{l}\text { Therapeutic } \\
\text { experiments in } \\
\text { Man } \\
\text { (a) Cause of } \\
\text { initial } \\
\text { lesion }\end{array}$ & Unsuccessful & $\begin{array}{r}\text { Prophylactic } \\
\text { coagulation }\end{array}$ & $\underset{\text { Minimum }}{1954}$ & $\begin{array}{l}\text { Nephrectomy } \\
\text { Adrenalectomy }\end{array}$ & \\
\hline & (b) $\begin{array}{l}\text { Initial } \\
\text { lesion }\end{array}$ & None & $\begin{array}{c}1925-1929 \\
\text { Closure of hole }\end{array}$ & None & $\begin{array}{l}\text { Sympathectomy } \\
\text { or } \\
\text { Hypotensors }\end{array}$ & \\
\hline
\end{tabular}

long, life is short, and judgment difficult". The Glasgow school of ophthalmology undoubtedly owes much in this matter to the late Prof. Arthur Ballantyne and to the help of the artist Mr. Gabriel Donald.

The second quality, perhaps a rarer one, is the capacity of the ophthalmoscopist to disabuse himself of preconceived ideas and to see things other than those he has been taught to see, and to be open to the significance of resemblances and recurrences. Leber, Gonin, and Ballantyne among others had this special talent. When generations of ophthalmoscopists have decided that the hole is a consequence of the retinal detachment or that the small red dots in the retina of a diabetic are haemorrhages, it takes a particular mind to think of other possibilities.

The third quality is an imagination to trace the pathological process. This, using the new-won facts, is capable of flashing a hypothesis which clicks all the facts into some order, as a magnet influences a heap of particles. This capacity is well illustrated by Leishman's work on hypertension. The multi-nuanced minutiae of calibre variation, arterio-venous crossing changes, colour, light reflex, and diameter changes could be disciplined into order only by an effort of this type of imagination.

Finally, we must mention parallel histological studies, together with the use of special techniques such as block examination or injection of the retinal vessels. In the diseases I have mentioned the histological studies have been more important in confirming than in initiating the discovery of the initial 
lesion. The significance of the hole in retinal detachment, of neovascularization in retrolental fibroplasia, or of the micro-aneurysm in diabetes could probably not have been revealed by the non-clinician alone. He would have been looking for a needle in a haystack, and even then, the needle might have disappeared like the hypertonic contraction of the retinal arteries after enucleation. Indeed the difference between the ophthalmoscopist and the histologist is a rather artificial one. In so far as histology, as a discipline, is chiefly distinguished by the magnification, with which tissues are observed, ophthalmoscopy fringes on the discipline because it permits a magnification, comparable to that of the lower power of the microscope, of tissues which are naturally fairly clear.

The time has now come to revert to the two questions posed at the outset - the logic of discovery in fundus diseases, and the relative roles of the clinician and the basic scientist.

None of the discoveries described phase by phase above was made by chance, but by painstaking, prolonged, purposeful labours spread over many years. No phase could come before its time but awaited the revelation of the preceding one. On the other hand within each phase some chance inspiration may play a part. Once Gonin had opened the fourth phase of our knowledge of retinal detachment, the principle of closure of the retinal hole, other methods of hole closure were bound to arrive. Indeed they did in the form of the happy thoughts of Weve (1932) with diathermy and of MeyerSchwickerath (1959) with photocoagulation. The initiation of a new phase is no chance discovery, but the development within each phase may be slow or rapid according to fortunate inspiration.

Regarding the relative roles of the ophthalmoscopist and the basic scientist, the discovery of the initial lesion is essentially the function of the ophthalmoscopist, and his discovery must precede investigation into causation.

The search for the cause of the initial lesion (Phase 3) is essentially the province of the basic scientist. The search for the cause of the initial lesion, as for example in diabetic retinopathy and hypertension, involves a knowledge of biochemistry and pathology which the clinical ophthalmologist can only rarely have. We expect much assistance from the biochemist and the experimental pathologist, especially in so much as they are engaged in the elucidation of the atheromatous process. This is possibly the cause of the initial lesion in a high percentage of retinal conditions, including venous occlusion, disciform degeneration, and senile macular degeneration. What may we in the light of present knowledge expect from the biophysicist with the psycho-physical and electro-physiological approaches to retinal disease? By these methods it is possible that he may be able to localize disturbances in the receptor or synaptic layers of the retina; and it is possible that he may be able to differentiate between disturbances of the photopic and scotopic systems. To this extent help may be obtained by discovering 
the site of the initial lesion, as for example in retinitis pigmentosa or Oguchi's disease. The biophysical approach to retinal dysfunction does not at present, however, appear to give help in the elucidation of the line of events leading to the initial lesion.

We have noted that Phase 2 depends on the ophthalmoscopist and Phase 3 on the basic scientist. Phase 4, like Phase 2, is essentially clinical. Treatment may be directed towards the cause of the initial lesion (e.g. hyperoxygenation in retrolental fibroplasia, or disturbance of renal or adrenal function in hypertension), or it may be limited to the initial lesion itself (e.g. closure of the retinal hole in detachment, or sympathectomy or hypotensors in hypertensive retinopathy). The ultimate aim should of course be preventive and therefore directed towards the cause of the initial lesion. An example of this is shown in the present studies in prophylactic coagulation of the retina.

So we are aware how in the processes of discovery, the clinician and realist alternates with the basic and abstract worker. It is like a relay race, each waiting until the other hands over the rod, and there is usually no gain in jumping one's turn. Application to the individual alternates with application to the idea, each being borne by and giving birth to the other. Although we have used developments in art to illustrate fundal discovery, it occurs to us that the artist might be helped by watching the mechanisms of fundal discovery.

The practical upshot of what I have said is that the ophthalmoscopist has had an important role in the elucidation of certain fundal diseases, and still has much to do. I have not said anything new. At best I have made aware what already is known to most of you, and certainly to the group of people with whom I had the honour to work a decade or two ago. Perhaps, after all, I chose this subject this evening in this place so that I could renew ophthalmic memories that I shall always cherish.

\section{REFERENCES}

Ashton, N. (1949). Brit. J. Ophthal., 33, 407.

, WARD, B., and SERPELL, G. (1953). Ibid., 37, 513.

BallaNTYNe, A. J. (1937). Trans. ophthal. Soc. U.K., 57, 301.

- and LOEWENSTEIN, S. (1943). Ibid., 63, 95.

BeCKer, B. (1952). Ann. intern. Med., 37, 273.

-, Allen, R., Winter, F. C., MAengwYN-Davies, G. D., and Friedenwald, J. S. (1954). Amer. J. Ophthal., 38, No. 1, Pt. 2, p. 53.

, LANG, C. A., and CHOW, B. F. (1953). J. clin. Nutr., 1. 417.

-, Maengwyn-Davies, G. D., Rosen, D., Friedenwald, J. S., and Winter, F. C. (1954). Diabetes, 3, 175.

Berkman. J., RIfKIN, H., and Ross, G. (1953). J. clin. Invest., 32, 415.

BRAUN, R. (1937). Arch. Augenheilk., 110, 535.

CAMPBELl, F. W. (1951). Trans. ophthal. Soc. U.K., 71, 287.

Campbell, K. (1951). Med. J. Aust., 2, 48.

Coccius, A. (1853). "Uber die Anwendung des Augen-spiegels nebst Angabe eines neuen Instrumentes", p. 125. Müller, Leipzig.

Crosse, V. M., and Evans, P. J. (1952). Arch. Ophthal. (Chicago), 48, 83.

Deutschmann, R. (1895). Beitr. Augenheilk., 2, 849. 
Duke-Elder, S. (1940). “"Text-book of Ophthalmology”, vol. 3, p. 2618. Kimpton, London. FrIEDENWALD, J. S. (1947). Arch. Ophthal. (Chicago), 37, 403. (1949). Amer. J. Ophthal., 32, 487.

(1952). J. Amer. med. Ass., 150, 969.

(1953). Diabetes, $2,237$.

, OWEns, W. C., and OWens, E. U. (1951). Trans. Amer. ophthal. Soc., 49, 207.

Goldblatt, H. (1937). Ann. intern. Med., 11, 69.

, LYNCH, J., HANZAL, R. F., and SummerVille, W. W. (1934). J. exp. Med., 59, 347.

GoldmanN, H. (1954). "Biomikroskopie des Auges". Rösch and Vogt, Berne.

GONIN, J. (1904). Ann. Oculist. (Paris), 132, 30. (1923). Klin. Mbl. Augenheilk., 71, 232.

(1925). Bull. Soc. Ophtal. Fr., 38, 614.

(1927). Ann. Oculist. (Paris), 164, 817. (1929). Klin. Mbl. Augenheilk., 83, 667.

Good, T. A., Good, R. A., Kelley, V. C., and Glick, D. (1951). Amer. J. Physiol., $166,555$.

HeATH, P. (1951). Amer. J. Ophthal., 34, 1249.

Holm, E. (1917). Klin. Mbl. Augenheilk., 59, 319.

IWANOFF (1869). v. Graefes Arch. Ophthal., 15 (2), 1.

JAEGER, E. (1856). "Beiträge zur Pathologie des Auges". Kaiserlich-Königlichen Hof und Staatsdruckerei, Vienna.

JefFerson, E. (1952). Arch. Dis. Childh., 27, 329.

Junius, P., and KuHnT, H. (1926). "Die Schiebenförmige Entartung der Netzhautmitte". Karger, Berlin.

KInSEY, V. E.(1956). A.M.A. Arch. Ophthal., 56, 481.

LEBER, T. (1882). Ber. ophthal. Ges., 14, 18.

LeISHMAN, R. (1957). Brit. J. Ophthal., 41, 641.

MacKenZIE, S., and NeTTleshiP, P. (1877). Roy. Lond. ophthal. Hosp. Rep., 9, 134.

McManus, J. F. A. (1950). Proc. Amer. Diabetes Ass., 1949, 9, 301.

MeYER-SchwicKERATH, G. (1959). "Licht Koagulation". Enke, Stuttgart.

Michaelson, I. C. (1948). Trans. ophthal. Soc. U.K., 68, 137.

(1955). "XVII Conc. Ophthal. Canada and U.S.A. 1954 Acta", vol. 1, p. 392. (1956). Brit. J. Ophthal., 40,527.

Oeller, J. (1905). "Atlas seltener ophthalmoskopischer Befunde". Bergmann, Wiesbaden.

OWENS, W. C., and OWENS, E. U. (1949). Amer. J. Ophthal., 32, 1.

Patz, A., Eastham, A., Higginbotham, D. H., and Kleh, T. (1953). Ibid., 36, 1511.

REESE, A. B. (1958). Ibid., 46, 156.

Rifkin, H., Solomon, S., and Lieberman, S. (1958). Diabetes, 7, 9.

Rintelen, F. (1937). Z. Augenheilk., 92, 306.

RYAN, H. (1952). Amer. J. Ophthal., 35, 329.

SZEWCZYK, T. S. (1952). Ibid., 35, 301.

TERRY, T. L. (1942). Ibid., 25, 1409.

VERHOEFF, F. H., and GrosSMAN, H. P. (1937). Arch. Ophthal. (Chicago), 18, 561.

VOGT, A. (1935). Klin. Mbl. Augenheilk., 95, 93.

WECKER, L. DE (1870). "Traité des maladies du fond des yeux", p. 153. Paris.

WEVE, H. (1932). "Zur Behandlung der Netzhautablösung mittels Diathermie". Berlin.

Wölfflin, E. (1926). v. Graefes Arch. Ophthal., 117, 33. 